\title{
A third myotomy with peroral endoscopic myotomy after two failed Heller myotomies
}
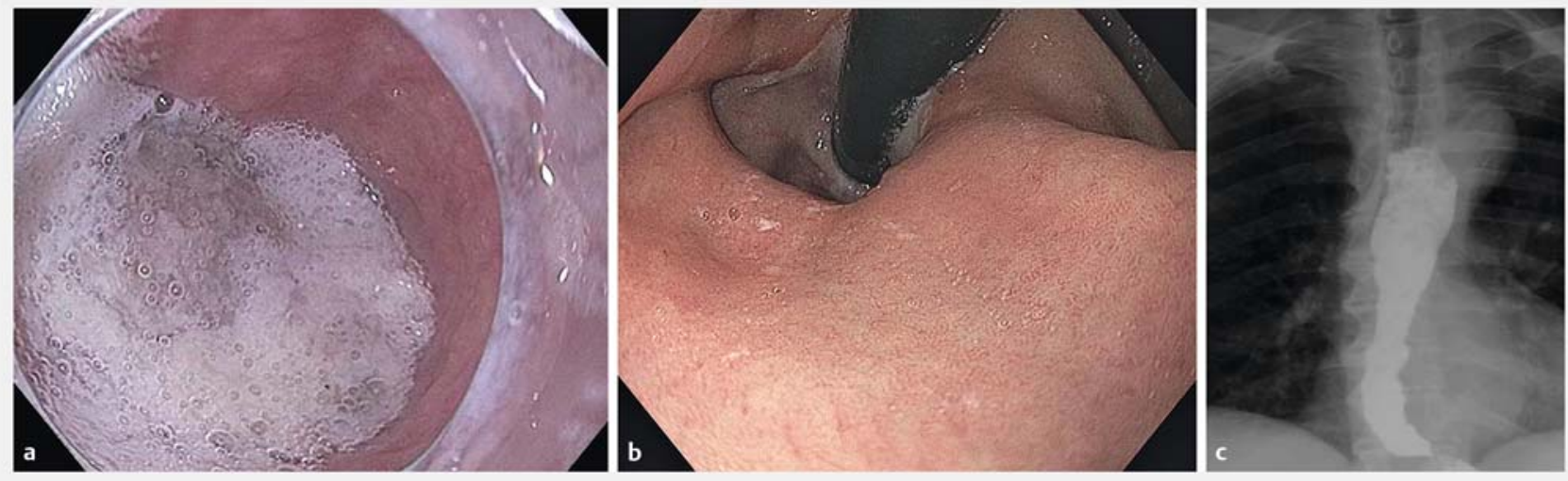

- Fig. 1 maging studies during work-up. a Esophagogastroduodenoscopy showed a dilated esophagus with retained frothy secretion. $\mathbf{b}$ The retroflexed endoscopic view showed a sliding hiatal hernia. The gastroesophageal area remained open, and squamous epithelium of the distal esophagus could be seen. c Cine esophagram revealed the classic bird's beak deformity of the distal esophagus.

Heller myotomy is the optimal surgical management for achalasia. Recurrent or persistent symptoms after surgical myotomy can occur in approximately $10 \%$ of patients [1, 2].

Failed Heller myotomy presents a diagnostic and therapeutic challenge. An inadequate surgical myotomy is the commonest cause of failure. The appropriate treatment for failed surgical myotomy is controversial. Peroral endoscopic myotomy (POEM) is a novel procedure for treatment of achalasia. POEM has been shown to be effective and safe for the treatment of patients in whom prior surgical myotomy has failed. It is unclear which procedure should be utilized in patients with failed double Heller myotomy.

We report the case of a 79-year-old man who had type II achalasia despite undergoing transabdominal Heller myotomy with partial posterior fundoplication (May 2007). The therapeutic result of surgery was inadequate and he subsequently underwent transthoracic myotomy and partial division of the diaphragmatic crus (September 2007), followed by two courses (August 2008 and July 2009) of balloon dilation using a $20 \mathrm{~mm}$ controlled radial expansion balloon. There was a mild improvement in his symptoms (transient $10 \%$ benefit at most according to the patient).

The patient underwent an extensive work-up, during which an esophagogastroduodenoscopy showed a dilated esophagus with retained secretion and tight lower esophageal sphincter (LES)
( $\triangleright$ Fig.1a). The retroflexed view showed a sliding hiatal hernia ( $\triangleright$ Fig.1 b). Cine esophagram revealed a classic bird's beak appearance ( $\mathbf{F i g} \mathbf{1} \mathbf{c}$ ). High resolution esophageal manometry (HREM) confirmed type II achalasia. Multiple therapeutic options were discussed with the patient and he opted for POEM.

\begin{tabular}{|lcc|}
\hline \multicolumn{1}{c}{ Pre myotomy Post myotomy } \\
\hline \multicolumn{1}{c|}{$\mathbf{3 0}$ cc } & & \\
Diameter (mm) & 6 & 14 \\
CSA (mm $\left.{ }^{2}\right)$ & 31 & 54 \\
Pressure (mmHg) & 21 & 31 \\
Distensibility index & 1.5 & 1.4 \\
\multicolumn{1}{|c|}{$\mathbf{4 0}$ cc } & & \\
Diameter (mm) & 7 & 15 \\
CSA (mm $\left.{ }^{2}\right)$ & 28 & 178 \\
Pressure (mmHg) & 28 & 29 \\
Distensibility index & 1 & 6.13
\end{tabular}

$\nabla$ Video 1 Clinical presentation and management of a patient with persistent symptoms after two failed Heller myotomies. 


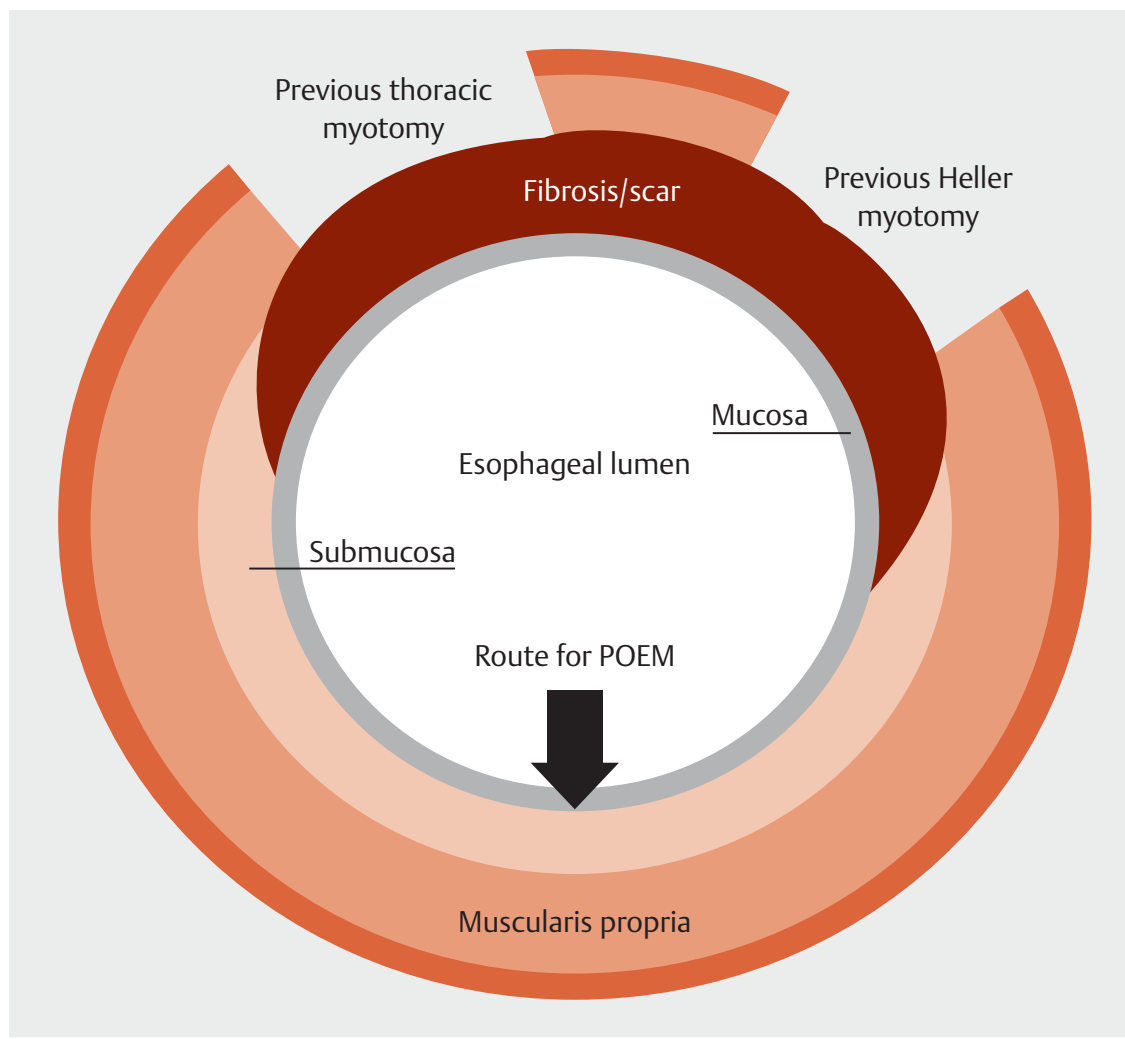

- Fig. 2 Anatomy of previous Heller myotomies. Transabdominal Heller was performed at the anterior wall in the 1-2 o'clock position, and transthoracic myotomy was performed at the left anterior wall in the 10-11 o'clock position. We elected to perform the peroral endoscopic myotomy procedure along the posterior esophageal wall to avoid the submucosal fibrosis and scars from previous myotomies.

- Table 1 Impedance planimetry before and after peroral endoscopic myotomy.

\begin{tabular}{|c|c|c|}
\hline & Before POEM & After POEM \\
\hline \multicolumn{3}{|l|}{$30 \mathrm{~mL}$} \\
\hline . Diameter, mm & 6 & 14 \\
\hline - CSA, mm² & 31 & 54 \\
\hline - Pressure, mmHg & 21 & 31 \\
\hline - Distensibility index & 1.5 & 1.4 \\
\hline \multicolumn{3}{|l|}{$40 \mathrm{~mL}$} \\
\hline . Diameter, mm & 7 & 15 \\
\hline - CSA, mm² & 28 & 178 \\
\hline - Pressure, mmHg & 28 & 29 \\
\hline - Distensibility index & 1.0 & 6.1 \\
\hline
\end{tabular}

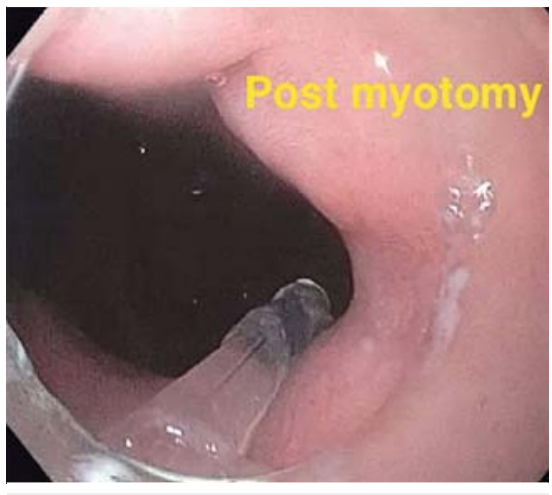

- Fig. 3 Endoscopic view of the lower esophageal sphincter after peroral endoscopic myotomy.

We elected to perform the standard POEM procedure (June 2016) along the posterior esophageal wall to avoid the submucosal fibrosis and scar from previous myotomies ( $>$ Fig. 2 ). At the end of the procedure, the adequacy of POEM was grossly assessed by smooth passage of the scope though the gastroesophageal junction ( $>$ Fig.3) and intraoperative impedance planimetry ( $\triangleright$ Table 1 ).

Following POEM, the patient was admitted to the hospital and remained nil per os. The following morning, cine esophagram showed no leakage. He was discharged home on a soft diet. At followup, his Eckardt scores was 0. HREM at 6 months revealed significant decrease in LES pressure.

POEM should be considered as an option for rescue therapy after failed double Heller myotomies. Triple myotomy is technically feasible, appears to be safe, and has good short-term efficacy in refractory achalasia. Posterior myotomy is recommended to avoid the submucosal fibrosis and scars of previous surgical myotomies.

Endoscopy_UCTN_Code_TTT_1AO_2AN

\section{Competing interests}

Dr. Khashab is a consultant for Boston Scientific. 
The Authors

Majidah Bukhari, Yamile Haito Chavez, Yen-I Chen, Olaya I. Brewer Gutierrez, Mouen A. Khashab

Division of Gastroenterology, Johns Hopkins Hospital, Baltimore, Maryland, USA

Corresponding author

Mouen A. Khashab, MD

Division of Gastroenterology and

Hepatology, Johns Hopkins Hospital, 1800

Orleans Street, Zayed Bldg, Suite 7125B,

Baltimore, MD 21287, United States

Fax: +1-443-6838333

mkhasha1@jhmi.edu

\section{References}

[1] Hunter JG, Trus TL, Branum GD et al. Laparoscopic Heller myotomy and fundoplication for achalasia. Ann Surg 1997; 225: 655-664; discussion 664-655

[2] Zaninotto G, Costantini M, Molena D et al. Treatment of esophageal achalasia with laparoscopic Heller myotomy and Dor partial anterior fundoplication: prospective evaluation of 100 consecutive patients. J Gastrointest Surg 2000; 4: 282-289

Bibliography

DOI https://doi.org/10.1055/s-0043-116488

Published online: 10.8.2017

Endoscopy 2017; 49: 1110-1112

(c) Georg Thieme Verlag KG

Stuttgart · New York

ISSN 0013-726X
ENDOSCOPY E-VIDEOS

https://eref.thieme.de/e-videos

回回 Endoscopy E-Videos is a free access online section, reporting 口if: on interesting cases and new techniques in gastroenterological endoscopy. All papers include a high quality video and all contributions are freely accessible online.

This section has its own submission website at

https://mc.manuscriptcentral.com/e-videos 